\title{
AN INVESTIGATION ON THE OPTIMISATION OF ELECTROCHEMICALLY PIGMENTED ALUMINIUM OXIDE SELECTIVE COLLECTOR COATINGS
}

\author{
F. Kadirgan ${ }^{1,2}$, M. Söhmen ${ }^{1}$, I.E. Türe ${ }^{1}$, Ş. Süzer ${ }^{3}$ J. Wetherilt ${ }^{1}$, A.Yazar ${ }^{1}$.
}

1. TÜBITAK, Marmara Research Centre, P.O. Box 21, 41470 Gebze, KOCAELI, TURKEY

2. Department of Chemistry, İstanbul Technical University, Maslak 80626 isTANBUL, TURKEY

3. Department of Chemistry, Bilkent University, Bilkent, ANKARA, TURKEY

\begin{abstract}
In order to produce selective coatings on aluminium substrates to be used as absorber plates in high efficiency solar collectors, nickel pigmentation has been applied to anodically oxidized surfaces. Optical and structural properties of electrochemically formed aluminium oxide films as function of electrolysis conditions such as, applied current, $\mathrm{pH}$, temperature and concentration of metal ions have been examined using electron spectroscopy and scanning electron microscopy. The optimisation of the absorptivity/emissivity ratio of the surfaces in terms of preparation conditions is described. Nickel pigmentation of porous aluminum surfaces was also investigated as a function of electrochemical pigmentation conditions. Mechanisms contributing to selectivity in anodically produced oxides and electrodeposits are discussed. Copyright (C) 1996 Published by Elsevier Science Ltd.
\end{abstract}

\section{KEYWORDS}

Selective surfaces; collectors; electrochemically pigmented aluminium.

\section{AN INVESTIGATION OF THE OPTIMISATION OF ELECTROCHEMICALLY PIGMENTED ALUMINIUM OXIDE SELECTIVE COLLECTOR COATINGS:}

Solar thermal collectors represent a wide-spread type of system for the conversion of solar energy. Radiation, convection and conduction are strongly coupled energy transport mechanisms in solar collector systems. The economic viability of lower temperature applications of solar energy may be improved by increasing the quantity of usable energy delivered per unit area of collector. This can be achieved by the use of selective black coatings which have a high degree of solar absorption, maintaining high energy input to the solar system while simultaneously suppressing the emission of thermal infrared radiation. 
Considerable effort has been expended on developing coatings and absorber materials having a high conversion efficiency (1-7) Commonly used methods for colouring anodised aluminium are spray pyrolysis, electro-plating, chemical conversion, thermal oxidation and sputtering techniques. Among these, the technique of electroplating is well established and commercially adapted for producing black $\mathrm{Ni}$ for use in evacuated tube collectors.

In this paper, an investigation into the optimisation of electrochemically pigmented aluminium oxide surfaces by nickel is reported.

\section{EXPERIMENTAL}

Samples consisting of $3 \times 2 \mathrm{~cm}$ flat pieces, were cut from sheets of commercial grade aluminium. After through rinsing, the samples were subjected to a chemical polishing treatment consisting of alkaline $(\mathrm{NaOH})$ and acid etchants $\left(\mathrm{H}_{3} \mathrm{PO}_{4}\right.$ and $\left.\mathrm{H}_{2} \mathrm{SO}_{4}\right)$.

\section{Anodisation}

A classic double walled three electrode cell coupled to a EG\&G 273 Potantiostat-Galvanostat system has been used for the oxidation of Al substrates. A lead cathode was used. Agitation was provided by magnetic stirring. The effects of temperature, applied current, $\mathrm{pH}$ and concentration of phosphoric acid were investigated.

\section{Pigmentation}

After anodisation, the samples were neutralised for $10 \mathrm{~min}$. in sodium bicarbonate in order to ensure that no phosporic acid was left on the surface of the aluminium oxide. Pigmentation was achieved using either nickel sulfate or acetate salts. The degree of pigmentation was investigated as a function of pigment concentration and applied potential. The pigmentation temperature was kept constant at $20 \pm 5^{\circ} \mathrm{C}$.

\section{Optical characterisation:}

Optical retection of the samples was measured in the visible and UV ranges using a Jasco $V 500$ spectrophotometer equipped with an ILN-472 integrating sphere. In the IR range, a Jasco FTIR/700 and RSA-FTIR 6 inch integrating sphere combination was used. Gold and teflon references were used to calibrate the systems in the IR and visible/UV respectively.

The pore diameter and the coating thickness on fractured aluminium substrates were studied using a scanning electron microscope.

ESCA measurements have been performed on samples cut out to $4 \times 12 \mathrm{~mm}$. dimensions using a Kratos ES 300 with MgK X-rays $(1253.6 \mathrm{eV})$. Spectra of Al metal, anodized Al together with one of the Ni pigmented aluminium oxide samples have been taken. In Ni-pigmented samples weak features assigned to Ni LMM Auger peaks are also observed. 


\section{RESULTS}

\section{Effects of anodisation parameters on the coatings}

Anodisation was undertaken under a constant current regime (from 2.5 to $10 \mathrm{~mA} / \mathrm{cm}_{2}$ ) in order to create homogenous surfaces. Applied current was found to be one of the major parameters that determined the thickness of the surface layer in addition to the geometry of the pores. Potential-time curves were recorded during the application of constant current. At higher currents the thickness and also the spacing between the pores was seen to increase.

The time of anodisation is seen to influence the thickness of the anodic oxide coating. However, after a certain length of time, the coating thickness tends to stabilise as the formation rate of the coating equals the dissolution rate of the oxide. AAS measurements on samples removed from the electrolyte solution confirm this.

The influences of the phosphoric acid concentration and of the temperature on the coatings were also investigated. An increase in either of these parameters was found to increase the dissolution rate of the oxide film.

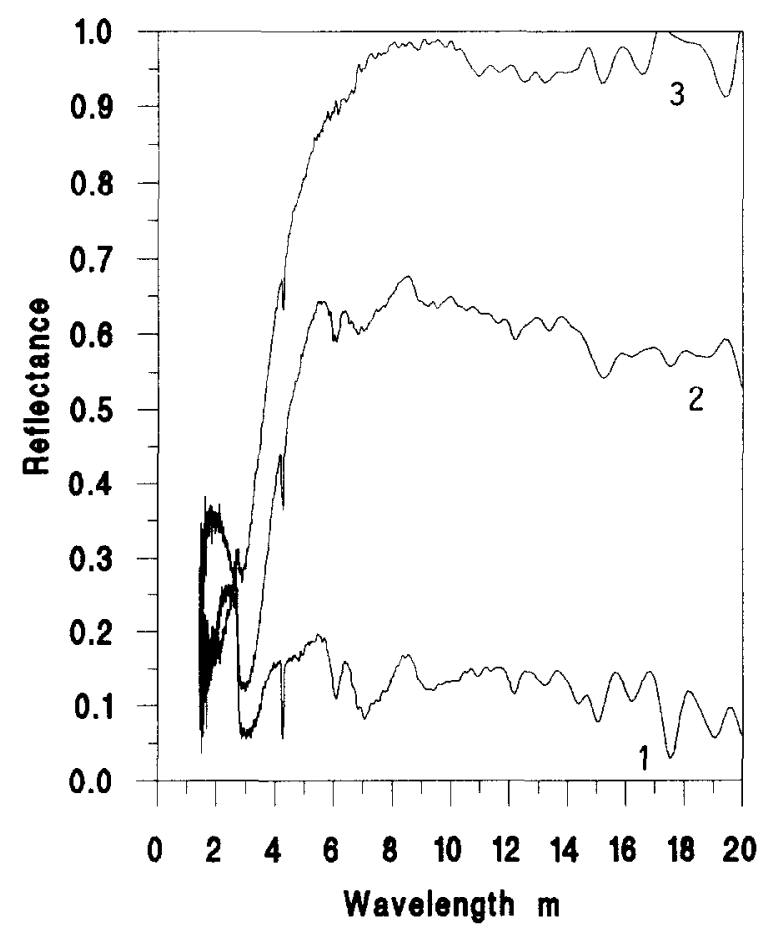

Fig 1: Spectra of the pigmented aluminium oxide at different conditions, 1 and 2 pigmented by $\mathrm{NiSO}_{4}, 3$ pigmented by $\mathrm{Ni}\left(\mathrm{CH}_{3} \mathrm{COO}\right)_{2}$ 


\section{Effect of pigmentation parameters}

Since the degree of pigmentation is important in determining the coatings produced, the dependence of the pigmentation on various parameters was investigated. The parameters include, concentration of the solutions, applied potential, and pigmentation time.

Optimum optical properties were obtained in coatings where the nickel sulphate and acetate used as a pigment covered the surface. The spectral reflectance curves can be seen clearly in Fig 1. which indicates an increase

in the selectivity of the coatings.

\section{CONCLUSION}

On the basis of the optical properties achieved, the selectivity of the coatings produced is reasonably high. It is seen that the emissivity of selective surface has depend on the thickness of oxide film. Since the sampling depth in XPS is approximately $50-60^{\circ} \mathrm{A}$, the surfaces of these samples consist mostly of $\mathrm{Al}, \mathrm{O}$ (and may be $\mathrm{H}$ ) and $\mathrm{Ni}$ is a minor component. This confirm that the pigment resides in pores on the oxide surface.

\section{REFERENCES}

1. Pavloviç, T., Ignatiev A. (2987). Optical properties of spectrally selective anodically coated electrolytically colored aluminium surfaces. Solar Energy Materials, 16, 319-331.

2. Inal, O.T., Scherer A. (1986). Optimization and microstructural analysis of electrochemically deposited selective solar absorber coatings. J. Materials Science, 21, 729-736.

3. Scherer, A., Inal, O.T., Pettit R.B. (1988). Modelling of degradation of nickel pigmented aluminium oxide photothermal collector coatings. J. Materials Science, 23, 1934-1942.

4. Andersson, A., Hunderi O., Granqvist C.G. (1980). Nickel pigmented anodic aluminium oxide for selective absorption of solar energy. J. Applied Physics, 51, 745-764.

5. Roos, A., Georgson M., Wackelgard E. (1991). Tin oxide coated anodized aluminium selective absorber surfaces I. Preparation and characterization. Solar Eneray Materials, 22, 15-18.

6. Keller, F., M. S. Hunter and D.L. Robinson (1953). Structural features of oxide coatings. on aluminium. J. Electrochem. Soc., 100, 411-419.

7. Bogaerts, F.W., Lambert M.C. (1983) Review Materials for photothermal solar energy conversion. J. Materials Science, 18, 2847-2875. 